\title{
Kinetics Modeling of the Carbon Vacancy Thermal Equilibration in $4 \mathrm{H}-\mathrm{SiC}$
}

\author{
Hussein M. Ayedh ${ }^{1, a^{*}}$, Roberta Nipoti ${ }^{2, b}$, Anders Hallén ${ }^{3, c}$ \\ and Bengt G. Svensson ${ }^{1, d}$ \\ ${ }^{1}$ University of Oslo, Department of Physics/SMN, N-0316 Oslo, Norway \\ ${ }^{2}$ CNR-IMM of Bologna, via Gobetti 101, I-40129 Bologna, Italy \\ ${ }^{3}$ Royal Institute of Technology, KTH-ICT, SE-164 40 Kista, Sweden

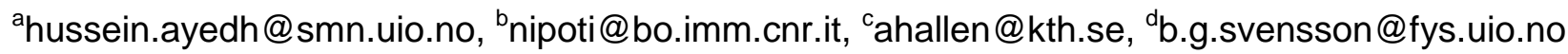

Keywords: 4H-SiC, Carbon Vacancy, Thermodynamic equilibrium, Kinetics Model, Diffusion

\begin{abstract}
The carbon vacancy $\left(\mathrm{V}_{\mathrm{C}}\right)$ is a major limiting-defect of minority carrier lifetime in n-type $4 \mathrm{H}-\mathrm{SiC}$ epitaxial layers and it is readily formed during high temperature processing. In this study, a kinetics model is put forward to address the thermodynamic equilibration of $\mathrm{V}_{\mathrm{C}}$, elucidating the possible atomistic mechanisms that control the $\mathrm{V}_{\mathrm{C}}$ equilibration under $\mathrm{C}$-rich conditions. Frenkel pair generation, injection of carbon interstitials $\left(\mathrm{C}_{\mathrm{i}}{ }^{\prime} \mathrm{s}\right)$ from the $\mathrm{C}$-rich surface, followed by recombination with $\mathrm{V}_{\mathrm{C}}$ 's, and diffusion of $\mathrm{V}_{\mathrm{C}}$ 's towards the surface appear to be the major mechanisms involved. The modelling results show a close agreement with experimental deep-level transient spectroscopy (DLTS) depth profiles of $\mathrm{V}_{\mathrm{C}}$ after annealing at different temperatures.
\end{abstract}

\section{Introduction}

The carbon vacancy $\left(\mathrm{V}_{\mathrm{C}}\right)$ is a prevailing point defect in $4 \mathrm{H}-\mathrm{SiC}$ epitaxial layers. It is reported as a major limiting defect of the minority charge carrier lifetime in n-type layers [1,2], with deep states in the $4 \mathrm{H}-\mathrm{SiC}$ bandgap leading to recombination/trapping of the charge carriers. In current state-ofthe-art as-grown epi-layers, the $\left[\mathrm{V}_{\mathrm{C}}\right]$ (brackets denote concentration) is typically in the $10^{12} \mathrm{~cm}^{-3}$ range and it is strongly enhanced, by about 2 orders of magnitude, after high-temperature processing [3]. Technologically, heat treatment at $\geq 1800{ }^{\circ} \mathrm{C}$ is important to achieve an adequate electrical activation of high fluence $\mathrm{Al}$ implanted regions, in order to realize low-resistivity p-type layers in bipolar power devices [4]. A formation enthalpy of $\sim 4.8 \mathrm{eV}$ under C-rich ambient conditions has been observed for $\mathrm{V}_{\mathrm{C}}$, both theoretically and experimentally $[3,5]$.

Two different methods have commonly been explored to reduce the $\left[\mathrm{V}_{\mathrm{C}}\right]$ in as-grown epi-layers: (i) thermal oxidation of the Si-terminated $4 \mathrm{H}-\mathrm{SiC}$ surface [6], and (ii) ion implantation in the near surface region followed by high temperature annealing [7,8]. In addition, we have recently demonstrated that annealing at the moderate temperature of $1500{ }^{\circ} \mathrm{C}$, establishing thermodynamic equilibrium under $\mathrm{C}$-rich surface conditions (carbon cap), also can reduce the $\left[\mathrm{V}_{\mathrm{C}}\right]$ to the low $10^{11} \mathrm{~cm}^{-3}$ range [9]. All these three approaches are based on the concept of injecting carbon interstitials $\left(C_{i}\right.$ 's) from the surface and subsequent recombination with $V_{C}$ 's in the epi-layer 'bulk'. However, the atomistic mechanisms controlling the equilibration of $\mathrm{V}_{\mathrm{C}}$ are still not fully known and this holds for their kinetics as well. In the present study, we put forward a kinetics model to elucidate the physical processes governing the equilibration process of $\mathrm{V}_{\mathrm{C}}$ under $\mathrm{C}$-rich ambient conditions.

\section{Kinetics Model}

In the kinetics model, the equilibrium concentration of $\mathrm{V}_{\mathrm{C}}\left(\left[\mathrm{V}_{\mathrm{C}}\right]_{\mathrm{Eq}}\right)$ during heat treatment under $\mathrm{C}$-rich surface conditions is assumed to be determined by two competing processes: (i) thermal generation of Frenkel pairs $\left(\mathrm{V}_{\mathrm{C}}\right.$ 's and $\mathrm{C}_{\mathrm{i}}$ 's) in the epi-layer 'bulk', and (ii) annihilation of $\mathrm{V}_{\mathrm{C}}$ 's via interaction with thermally injected $\mathrm{C}_{\mathrm{i}}$ 's from the $\mathrm{C}$-cap. Accordingly, the following partial differential equations can be derived from the theory of diffusion-limited reactions [10] and then 
numerically solved to obtain one-dimensional $\left[\mathrm{V}_{\mathrm{C}}\right]$ versus depth profiles during elevated heat treatments,

$$
\begin{aligned}
& \frac{\partial\left[V_{C}\right]}{\partial t}=G_{V_{C}}+\frac{\partial}{\partial x}\left(D_{V_{C}} \frac{\partial\left[V_{C}\right]}{\partial x}\right)-4 \pi R\left(D_{C_{i}}+D_{V_{C}}\right)\left[C_{i}\right]\left[V_{C}\right] \\
& \frac{\partial\left[C_{i}\right]}{\partial t}=G_{C_{i}}+\frac{\partial}{\partial x}\left(D_{C_{i}} \frac{\partial\left[C_{i}\right]}{\partial x}\right)-4 \pi R\left(D_{C_{i}}+D_{V_{C}}\right)\left[C_{i}\right]\left[V_{C}\right] .
\end{aligned}
$$

Here, $G_{V_{C}}$ and $G_{C_{i}}$ are the thermal generation rates of $\mathrm{V}_{\mathrm{C}}$ and $\mathrm{C}_{\mathrm{i}}$, respectively, and they were set equal in the model since $V_{C}$ 's and $C_{i}$ 's are assumed to be generated as Frenkel pairs in the epi-layer 'bulk' [3]. Furthermore, $t$ refers to the annealing time, and $x$ to the sample depth. $D_{C_{i}}$ and $D_{V_{C}}$ are the diffusion coefficients of $C_{i}$ and $V_{C}$ respectively, and $R$ is the reaction capture radius between $V_{C}$ and $\mathrm{C}_{\mathrm{i}}$. The last term on the right side of Eq. 1 and Eq. 2 represents the recombination rate between $\mathrm{V}_{\mathrm{C}}$ and $\mathrm{C}_{\mathrm{i}}$. The $\left[\mathrm{V}_{\mathrm{C}}\right]_{\mathrm{Eq}}$ will be reached at each temperature when the variation of $\left[\mathrm{V}_{\mathrm{C}}\right]$ with $t$ approaches zero, yielding,

$$
\left[V_{C}\right]_{\mathrm{Eq}}=\frac{G_{V_{C}}+\frac{\partial}{\partial x}\left(D_{V_{C}} \frac{\partial\left[V_{C}\right]}{\partial x}\right)}{4 \pi R\left(D_{C_{i}}+D_{V_{C}}\right)\left[C_{i}\right]}
$$

$G_{V_{C}}, D_{V_{C}}, D_{C_{i}}$, and the injected $\left[C_{i}\right]_{x=0}$ are used in the model as the fitting parameters to reproduce the experimental data, and they are all expressed by an Arrhenius equation,

$$
X=X_{o} \exp \left(\frac{-E_{a X}}{k T}\right)
$$

Here $X$ represents the fitting parameter (i.e $G_{V_{C}}, D_{V_{C}}, D_{C_{i}}$, or $\left[C_{i}\right]_{x=0}$ ), $X_{o}$ is a pre-exponential factor, $E_{a X}$ is the activation energy for the process $X, k$ is the Boltzmann constant, and $T$ is the absolute temperature. In addition, the following initial conditions are applied,

$$
\begin{array}{ll}
{\left[C_{i}\right]_{t=0}=0,} & \text { for } x>0 \\
{\left[V_{C}\right]_{t=0}=\left[V_{C}\right]_{0}} & \text { for } x \leq 10 \mu \mathrm{m} \\
{\left[V_{C}\right]_{t=0}=100 \times\left[V_{C}\right]_{0}} & \text { for } x>10 \mu \mathrm{m} .
\end{array}
$$

Here, $\left[V_{C}\right]_{0}$ represents the initial $\left[\mathrm{V}_{\mathrm{C}}\right]$ at $t=0$, which is expected to be a few orders of magnitude higher in the highly n-type substrate $(x>10 \mu \mathrm{m})$ relative to the lightly n-type epi-layer $(x \leq 10 \mu m)$, and the substrate in this case is assumed to serve as a sink for the thermally generated and rapidly migrating $C_{i}$ 's. The $C$-cap /epi-layer interface is treated as a reflective boundary for $V_{C}$, while the epi-layer/substrate interface is regarded as a reference plane with no influence on the flux of $\mathrm{C}_{\mathrm{i}}$ 's and $\mathrm{V}_{\mathrm{C}}$ 's.

\section{Results and Discussion}

Figure 1 shows simulated depth profiles of $\left[\mathrm{V}_{\mathrm{C}}\right]$ for a wide concentration range $\left(10^{11}-10^{14} \mathrm{~cm}^{-3}\right)$. The profiles exhibit good agreement with experimental deep level transient spectroscopy (DLTS) depth profiles of $\mathrm{V}_{\mathrm{C}}$ in epitaxial samples post-growth heat treated between 1500 and $1950{ }^{\circ} \mathrm{C}$, illustrating the validity of the model. The simulation results emphasize the significance of both the competing processes (i) and (ii), mentioned above, for the equilibration of $\left[\mathrm{V}_{\mathrm{C}}\right]$. The profiles show that $\mathrm{V}_{\mathrm{C}}$ formation dominates at high temperatures where the generated $\left[\mathrm{V}_{\mathrm{C}}\right]$ is much higher than the injected $\left[\mathrm{C}_{\mathrm{i}}\right]$. In this case, the annihilation of $\mathrm{V}_{\mathrm{C}}$ 's appears to be limited to a restricted region in the vicinity of the surface, yielding a continuous diffusion of $\mathrm{V}_{\mathrm{C}}$ from the epi-layer 'bulk' towards the 
surface due to the concentration gradient. This explains the observed decrease of $\left[\mathrm{V}_{\mathrm{C}}\right]$ towards the surface in the samples treated at $\geq 1800{ }^{\circ} \mathrm{C}$, implying that thermodynamic equilibrium does not truly hold at depths $>2 \mu \mathrm{m}$, but rather steady-state conditions which are rapidly established at high temperatures. While the $\mathrm{V}_{\mathrm{C}}$ profile becomes essentially flat in the samples annealed at $\leq 1600{ }^{\circ} \mathrm{C}$ for which the near surface trapping of injected $\mathrm{C}_{\mathrm{i}}$ 's is less because of the lower $\left[\mathrm{V}_{\mathrm{C}}\right]$. At moderate temperatures $\left(\leq 1600{ }^{\circ} \mathrm{C}\right.$ ), the injected $\mathrm{C}_{\mathrm{i}}$ 's can diffuse deeper into the epi-layer bulk and the annihilation of $\mathrm{V}_{\mathrm{C}}$ 's takes place in the entire layer $(10 \mu \mathrm{m})$. Hence, the injection of $C_{i}$ 's is the process controlling the equilibration kinetics at moderate temperatures.

The pre-exponential factors and activation energies of the fitting parameters used in the model, $G_{V_{C}}, D_{V_{C}}, D_{C_{i}}$ and $\left[C_{i}\right]_{x=0}$, were extracted from the Arrhenius plots in Figs. 2(a) and 2(b). The deduced activation energy for the generation rate of $\mathrm{V}_{\mathrm{C}}\left(E_{G_{V C}}\right)$ is about $6.3 \mathrm{eV}$, which is $\sim 1.5 \mathrm{eV}$ higher than the $\mathrm{V}_{\mathrm{C}}$ formation energy of $4.8 \mathrm{eV}$ determined experimentally and theoretically for $\mathrm{V}_{\mathrm{C}}$ in the neutral charge state [3,5,9]. This reflects that in the Frenkel pair, $\mathrm{V}_{\mathrm{C}}$ and $\mathrm{C}_{\mathrm{i}}$, formation process, the $\mathrm{C}_{\mathrm{i}}$ diffuses away and leaves behind the less mobile $\mathrm{V}_{\mathrm{C}}$. Accordingly, the deduced activation energy of the $V_{C}$ (and $C_{i}$ ) generation rate is given by the sum of the $V_{C}$ formation energy and the migration energy of $\mathrm{C}_{\mathrm{i}}$. Therefore, the $\mathrm{C}_{\mathrm{i}}$ migration energy $\left(E_{M_{C i}}\right)$ becomes $\sim 1.5 \mathrm{eV}$, and this value is further corroborated by the results in Ref. [11]. As a result, values of $D_{C_{i}}$ can be assumed in the simulations and then also $\left[C_{i}\right]_{x=0}$ can be determined. Here, it should be mentioned that based on Eq. 3, the values of $\left[C_{i}\right]_{x=0}$ and $D_{C_{i}}$ can be decoupled only if $D_{C_{i}}$ is known, since identical $\left[\mathrm{V}_{\mathrm{C}}\right]$ versus depth profiles are obtained at a given temperature as long as the product $\left(D_{C_{i}} \times\left[C_{i}\right]_{x=0}\right)$ remains constant. Knowing the contribution of $D_{C_{i}}$, we then arrive at a value of $\sim 1.7 \mathrm{eV}$ for the activation energy of $\mathrm{C}_{\mathrm{i}}$ injection $\left(E_{i n j}\right)$ in a close agreement with the activation energy for the flux of injected $C_{i}$ reported in Ref. [12]. The deduced activation energy for

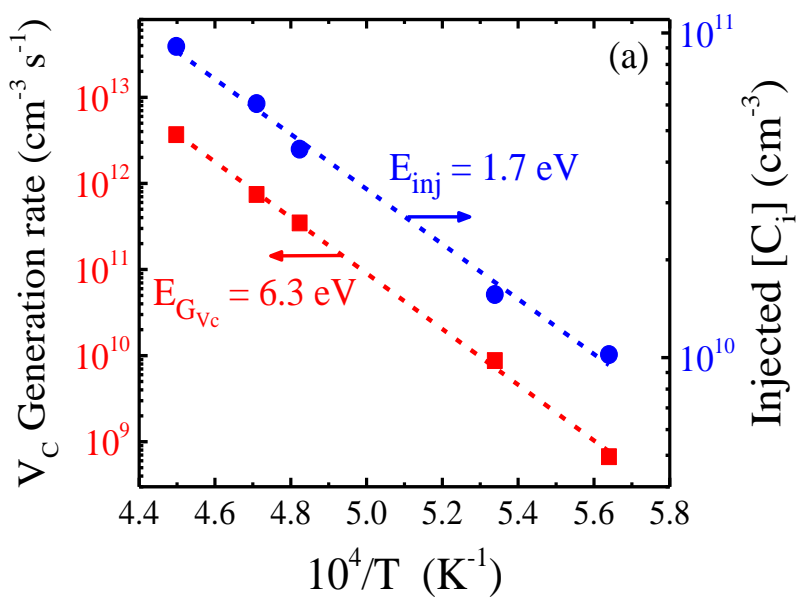

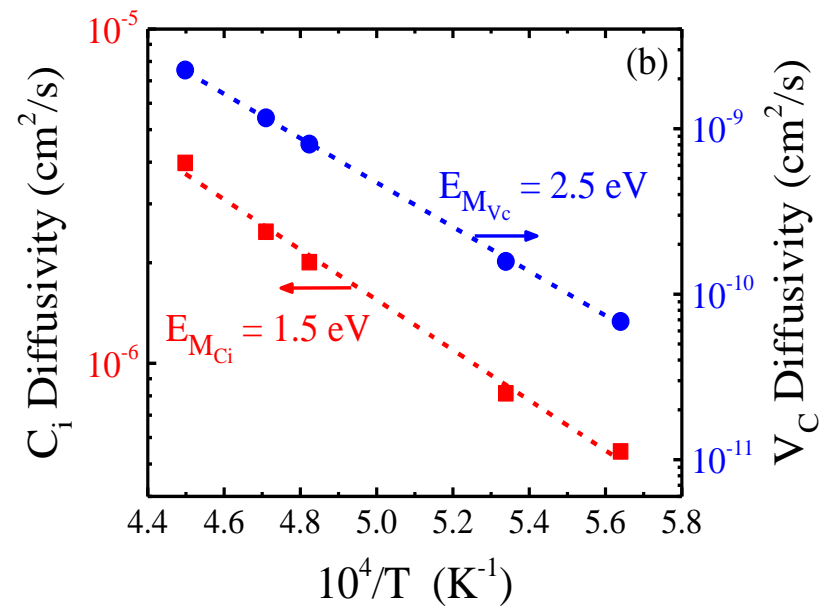

Figure 2. (a) The extracted values of the $\mathrm{V}_{\mathrm{C}}$ generation rate $\left(G_{V_{C}}\right)$ (left $\mathrm{Y}$-axis) and the injected $\left[\mathrm{C}_{\mathrm{i}}\right]$ at $\mathrm{x}=0$ (right $\mathrm{Y}$-axis) from the simulations as a function of the reciprocal absolute annealing temperature.

(b) Simulated values of the $\mathrm{C}_{\mathrm{i}}$ diffusion coefficient $\left(D_{C_{i}}\right)$ (left $\mathrm{Y}$-axis) and the $\mathrm{V}_{\mathrm{C}}$ diffusion coefficient $\left(D_{V_{C}}\right)$ (right $\mathrm{Y}$-axis) versus the reciprocal absolute annealing temperature. 
$\mathrm{V}_{\mathrm{C}}$ migration $\left(E_{M_{V C}}\right)$ is $\sim 2.5 \mathrm{eV}$ as shown in Fig. 2(b), and $D_{C_{i}}$ is $\sim 3-4$ orders of magnitude higher than $D_{V_{C}}$ at temperatures above $1500{ }^{\circ} \mathrm{C}$. Thus, $D_{V_{C}}$ in the denominator of Eq. 3 has a negligible influence on $\left[\mathrm{V}_{\mathrm{C}}\right]_{\mathrm{Eq}}$, although $D_{V_{C}}$ plays a significant role at high temperatures $\left(\geq 1800{ }^{\circ} \mathrm{C}\right)$ when the generation rate of $\left[\mathrm{V}_{\mathrm{C}}\right]$ is high and the trapping of injected $\mathrm{C}_{\mathrm{i}}$ 's near the surface is strong.

Finally, the model provides a possibility to estimate the equilibration time at different processing temperatures and the influence of the initial concentration of $\mathrm{V}_{\mathrm{C}}$. At the moderate temperature of $1500{ }^{\circ} \mathrm{C}$, at which the $\mathrm{V}_{\mathrm{C}}$ annihilation is the governing process, it was experimentally reported that $\left[\mathrm{V}_{\mathrm{C}}\right]_{\mathrm{Eq}}$ occurs after about $40 \mathrm{~min}$ for as-grown epi-layers $\left(\left[\mathrm{V}_{\mathrm{C}}\right]_{\mathrm{t}=0} \sim 4 \times 10^{12} \mathrm{~cm}^{-3}\right)$ with a thickness of $10 \mu \mathrm{m}$ [9]. Further, in a sample first treated at $1950{ }^{\circ} \mathrm{C}$ (followed by rapid cooling) yielding $\left[\mathrm{V}_{\mathrm{C}}\right]$ $\approx 2 \times 10^{14} \mathrm{~cm}^{-3}$ and then re-annealed at $1500{ }^{\circ} \mathrm{C}$, a duration of $3 \mathrm{~h}$ was found to be sufficient to reach the $1500{ }^{\circ} \mathrm{C}$ equilibrium. The simulation results exhibit a good agreement with both of these experimental observations, predicting an equilibration time of $\sim 40 \mathrm{~min}$ and $\sim 4.5 \mathrm{~h}$ at $1500{ }^{\circ} \mathrm{C}$ when $\left[\mathrm{V}_{\mathrm{C}}\right]_{\mathrm{t}=0}$ equals $4 \times 10^{12} \mathrm{~cm}^{-3}$ and $2 \times 10^{14} \mathrm{~cm}^{-3}$, respectively. The model shows that $\left[\mathrm{V}_{\mathrm{C}}\right]_{\mathrm{Eq}}$ of $\sim 4 \times 10^{10} \mathrm{~cm}^{-3}$ can be reached after $1400{ }^{\circ} \mathrm{C}$ annealing if the duration employed is sufficient. This estimation provides guidance on how to control the $\left[\mathrm{V}_{\mathrm{C}}\right]$ to enhance the charge carrier lifetime in thick n-type epi-layers for high voltage $4 \mathrm{H}-\mathrm{SiC}$ bipolar devices.

\section{Summary}

A defect kinetics model has been proposed in order to elucidate the physical processes controlling the equilibration of $\mathrm{V}_{\mathrm{C}}$ in $4 \mathrm{H}-\mathrm{SiC}$ epi-layers. The model assumes thermal generation of $\mathrm{V}_{\mathrm{C}}$ 's by a bulk (Frenkel pair) process, injection of $\mathrm{C}_{\mathrm{i}}$ 's from the surface under $\mathrm{C}$-rich conditions (C-cap) followed by recombination with $\mathrm{V}_{\mathrm{C}}$ 's in the bulk, and diffusion of $\mathrm{V}_{\mathrm{C}}$ 's towards the surface, as the major processes during the equilibration. The simulated depth profiles of $\left[\mathrm{V}_{\mathrm{C}}\right]$ exhibit good quantitative agreement with DLTS experimental results, corroborating the validity of the model. In the model, both $C_{i}$ and $V_{C}$ are assumed to be mobile and activation energies of $\sim 1.5$ and $2.5 \mathrm{eV}$ for the migration of $\mathrm{C}_{\mathrm{i}}$ and $\mathrm{V}_{\mathrm{C}}$ are deduced, respectively, in a good agreement with theoretical values reported in the literature.

\section{Acknowledgments}

Financial support by the Norwegian Research Council (FRINATEK program - WEDD project), and the University of Oslo and the Norwegian Research Council through the frontier research project FUNDAMeNT (no. 251131, ToppForsk program) are gratefully acknowledged.

\section{References}

[1] P. B. Klein, et al., Appl. Phys. Lett. 88 (2006) 052110.

[2] N. T. Son, et al., Phys. Rev. Lett. 109 (2012) 187603.

[3] H. M. Ayedh, et al., J. Appl. Phys. 115 (2014) 012005.

[4] R. Nipoti, et al., Appl. Phys. Express 4 (2011) 111301.

[5] T. Hornos, A. Gali and B.G. Svensson, Mater. Sci. Forum 679-680 (2011) 261.

[6] T. Hiyoshi and T. Kimoto, Appl. Phys. Express 2 (2009) 041101.

[7] L. Storasta and H. Tsuchida, Appl. Phys. Lett. 90 (2007) 062116.

[8] H. M. Ayedh, A. Hallén and B. G. Svensson, J. Appl. Phys. 118 (2015) 175701.

[9] H. M. Ayedh, R. Nipoti, A. Hallén and B. G. Svensson, Appl. Phys. Lett. 107 (2015) 252102.

[10] T. R. Waite, Phys. Rev. 107 (1957) 463.

[11] M. Bockstedte, A. Mattausch and O. Pankratov, Phys. Rev. B 68 (2003) 205201.

[12] K. Kawahara, J. Suda and T. Kimoto, J. Appl. Phys. 111 (2012) 053710. 